\title{
Continuous spinal
} anaesthesia using a standard epidural set for extracorporeal shockwave lithotripsy

\author{
Ze'ev Shenkman MD, \\ Leonid A. Eidelman MD, \\ Shamay Cotev MD
}

\begin{abstract}
Purpose: Continuous spinal anaesthesia (CSA) offers considerable advantages over "single shot" spinal or epidural anaesthesia since it allows titration of anaesthesia using small doses of local anaesthetics (LA). We evaluated the feasibility of CSA using a standard epidural set for extracorporeal shockwave lithotripsy (ESWL).

Methods: Charts of 100 consecutive CSAs for ESWL were retrospectively reviewed. Lumbar CSA was performed using a 20G epidural catheter through an 18G Tuohy needle. The CSA was preplanned, or followed inadvertent dural puncture. Small LA boluses were injected to achieve the desired sensory level of anaesthesia. Demographic data, anaesthetic duration, LA doses, the most cephalad sensory level to pinprick, arterial blood pressure, heart rate, use of systemic sympathomimetics and complications were recorded.
\end{abstract}

Results: Mean age was $66.2 \pm 9.9$ (SD). The ASA status was III-N in 54.1\% and 5.5\% of the preplanned and inadvertent patients, respectively. In 85 anaesthetics, hyperbaric bupivacaine $0.1 \%(9.7 \pm 7.5 \mathrm{mg})$ was used as the sole anaesthetic. Sensory level was $T_{4}-T_{8}$. Maximal decrease in systolic and diastolic blood pressures and heart rate was 19.0 $\pm 9.8 \%, 13.4 \pm 13.3 \%$, and $7.2 \pm 11.7$ respectively. Intravenous sympathomimetics were used in nine of $82(11.0 \%)$ preplanned, and in six of 18 (33.3\%) inadvertent anaesthetics. Post dural puncture headache appeared following two of $82(2.5 \%)$ preplanned, and four of $18(22.2 \%)$ inadvertent anaesthetics. No postanaesthetic neurological deficit was detected.

Conclusion: Continuous spinal anaesthesia, using a standard epidural set and hyperbaric bupivacaine is feasible for ESWL in high risk patients. Inadvertent dural puncture does not preclude CSA under these circumstances.

Objectif : Parce qu'elle permet de titrer l'anesthésie avec des doses minimes d'anesthésique local (AL), la rachianesthésie continue (RAC) offre des avantages considérables sur la rachianesthésie et l'épidurale à injection unique. Nous avons recherché s'il était possible d'administrer la RAC avec un plateau épidural standard pour la lithotripsie extracorporelle par ondes de choc (LFOC).

Méthodes : L'étude a consisté à revoir rétrospectivement les dossiers de 100 interventions de LEOC consécutives. La rachianesthésie lombaire était réalisée avec un cathéter épidural $20 \mathrm{G}$ introduit à travers une Tuohy 18G. La RAC faisait partie de la planification oniginale ou suivait une ponction accidentelle de la dure-mère. Le niveau sensoriel d'anesthésie désiré était atteint par l'injection de petits bolus d'AL. Les données démographiques, la durée de l'anesthésie, les doses d'AL, le niveau céphalique maximal déterminé par piqûre, la pression artérielle, la fréquence cardiaque, l'utilisation de sympathicomimétiques et les complications ont été enregistrées.

Resultats : L'áge moyen était 66,2 $\pm 9,9$ (É). Le pourcentage d'état physique ASA III-N représentait 54,1\% des patients prévus et de $5.5 \%$ chez les patients imprévus. Quatre-vingt-cinq patients n'ont reçu que de la bupivacaine hyperbare à $0.1 \%(9.7 \pm 7.5 \mathrm{mg})$. Le niveau sensoriel atteint se situait entre $T_{4}$ et $T_{8}$. Les chutes maximales des pressions systolique et diastolique et de la fréquence cardiaque étaient de $19 \pm 9,8 \%, 13,4 \pm 13,3 \%$ et 7,2 $\pm 11,7$ bpm. II a fallu administrer des sympathicomimétiques intraveineux à 9 des $82(11,0 \%)$ des patients prévis et à six des 18 (33,3\%) des imprévus. Une céphalée postrachianesthésie s'est manifestée après 2 des 82 (2,5\%) RAC prévues et quatre de $18(22,2 \%)$ imprévues. II n'y a pas eu de déficit neurologique.

Conclusion : II est possible d'administrer une rachianesthésie continue avec un plateau épidural standard et de la bupivacaïne hyperbare pour la LEOC chez des patients à haut risque. Une ponction accidentelle de la duremère n'exclut pas la RAC dans ces circonstances.

From the Department of Anesthesiology and CCM, Hadassah University Hospital and the Hebrew University Hadassah School of Medicine, Jerusalem, Israel. Address correspondence to: Ze'ev Shenkman MD, Department of Anesthesia/Bader 3, The Children's Hospital Medical Center, 300 Longwood Avenue, Boston, MA 02115; Phone: 617-355-6225; Fax: 617-355-7887.

Accepted for publication June 22, 1997 


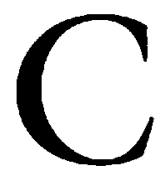

ONTINUOUS spinal anaesthesia (CSA) offers considerable advantages over "single shot" spinal or epidural anaesthesia since it allows administration of well-controlled anaesthesia using small doses of local anaesthetics (LA). ${ }^{1}$ Its use has been reported for various procedures such as Caesarean section, ${ }^{1}$ orthopaedic, ${ }^{1-3}$ trauma ${ }^{3}$ or peripheral vascular ${ }^{4}$ procedures in the lower limb, lower abdominal and pelvic surgery, ${ }^{1,5}$ urological procedures, ${ }^{1}$ and for gynaecological, rectal and perineal surgery. ${ }^{1}$ It has been used in old $^{2,6}$ and high-risk ${ }^{1,2,4-6}$ patients. However, CSA has not gained wide popularity because of the fear of post anaesthetic cauda equina syndrome, ${ }^{3,6-9}$ and because of the difficulty in placing microcatheters into the subarachnoid space. ${ }^{3,7}$

The patient population referred for extracorporeal shockwave lithotripsy (ESWL) usually includes elderly patients, many of whom suffer from coexisting systemic illness. Moreover, patient positioning and immersion in the water bath can lead to haemodynamic changes. ${ }^{10}$

In this study, we analysed retrospectively 100 consecutive CSAs for ESWL using a standard epidural set, performed in 92 patients.

\section{Methods}

Subjects: Of the 1146 ESWLs performed in our hospital, all with anaesthesia, over five years, $100(8.7 \%)$ were performed with CSA.

Procedures: The CSAs were performed using a standard epidural set (Perifix, B. Braun Melsungen AG, Germany). The patients were positioned in the seated or the lateral decubitus position, and an 18G Tuohy needle was inserted into the subarachnoid space in the $\mathrm{L}_{2}-\mathrm{L}_{3}$, $\mathrm{L}_{3}-\mathrm{L}_{4}$, or $\mathrm{L}_{4}-\mathrm{L}_{5}$ intervertebral space, through which a standard $20 \mathrm{G}$ epidural catheter was introduced. The catheter was threaded $3-4 \mathrm{~cm}$ into the subarachnoid space. Paraesthesia were uncommon and, when elicited, the catheter was slightly withdrawn. Location of the needle and the catheter in the subarachnoid space was verified by obtaining a free flow of cerebrospinal fluid (CSF). When epidural anaesthesia was originally planned, but the dura was inadvertently penetrated, the catheter was inserted through the needle, and continuous spinal, rather than epidural anaesthesia was conducted. Local anaesthetics (e.g., $1-3 \mathrm{mg}$ boluses of bupivacaine $0.1 \%$ ) were injected into the subarachnoid space, until the desired sensory level of anaesthesia relative to the location of the stone, was reached. The selection of anaesthetic agent was according to the preference of the consultant anaesthetist. Routine monitoring included pulse oximetry, ECG and non-invasive (or invasive) mea- surement of arterial blood pressure (BP). Usually, noninvasive BP was measured every 1-2.5 min until approximately $10 \mathrm{~min}$ after anaesthetic induction, and later, every 2.5-5 min until completion of the procedure. Sympathomimetic agents were administered $i p$ when systolic BP decreased below $100 \mathrm{mmHg}$, or when the anaesthetist has considered that the value was too low (particularly in hypertensive patients). The patients were then transferred to the hydraulic chair of the lithotriptor (HM3 Dornier, Munchen, Germany) and immersed into the warm water bath (about $36^{\circ} \mathrm{C}$ ) where the shockwaves were delivered. After the procedure, the spinal catheter was withdrawn and the patients were transferred to the post anaesthesia care unit. For all patients, the following variables were recorded: age, weight, ASA physical status, duration of procedure, anaesthetic drugs and doses, the most cephalad sensory level to pinprick, the use of additional systemic sedatives and analgesics, baseline and minimal BP and heart rate (HR), the use of sympathomimetic drugs, volume of iv fluid, and perianaesthetic complications. The last included technical failure to thread the catheter, evidence of inadequate anaesthesia (either insufficient sensory level or quality of the block), "high" spinal anaesthesia, hypotension, bradycardia, post dural puncture headache (PDPH) and adverse neurological sequelae including persistent pain, motor or sensory deficits, haematoma or infection.

\section{Results}

Ninety-two patients underwent 100 anaesthetics for lithotripsy: 86 had one anaesthetic, five had two and one had four anaesthetics.

Of the 100 CSAs, 82 were preplanned (CSA-P), and 18 (in 18 patients), followed inadvertent dural puncture following attempted epidural blockade (CSA-I). Fiftynine $(64.1 \%)$ of patients were male. The mean age of the patients was $66.2 \pm 9.9(\mathrm{SD})$ yr and weight was $78.5 \pm$ $13.9 \mathrm{~kg}$. Forty-one patients (44.6\%) were graded as ASA physical status III or IV. Of these, 40 were in the CSA$P$ group (54.1\% of the 74 patients in the subgroup), as opposed to only one patient (5.5\%) in the CSA-I group. Twenty-one patients had one concurrent disease, 21 had two, 18 had three, 13 had four, six had five, one had six concurrent diseases, and one patient had ten concurrent diseases (Table I). In 85 anaesthetics, hyperbaric, diluted bupivacaine was used as the sole intrathecal anaesthetic drug. It was prepared as a $0.1 \%$ solution by diluting plain $0.5 \%$ bupivacaine (Astra, Sodertalje, Sweden) in $10 \%$ glucose (prepared by our institutional pharmacy). The mean total administered dose of bupivacaine was $9.7 \pm 7.5$ (SD) $\mathrm{mg}$. Lidocaine $2 \%$ was added intrathecally in two patients and used as the sole agent in one additional patient. Intrathecal fentanyl in doses of 
TABLE I Pre-existing medical conditions in 92 patients

\begin{tabular}{llll}
\hline Condition & $n(\%)$ & Condition & $n(\%)$ \\
\hline ischaemic heart disease & $25(27.2)$ & COPD, bronchial asthma & $9(9.8)$ \\
valvular heart disease & $3(3.3)$ & pulmonary hypertension & $1(1.1)$ \\
dysrrhythmia/conduction defect & $12(13.0)$ & diabetes mellitus & $19(20.7)$ \\
cardiomyopathy/cardiomegaly & $7(7.6)$ & metabolic/other hormonal ${ }^{\dagger}$ & $7(7.6)$ \\
congestive heart failure & $7(7.6)$ & obesity/morbid obesity & $29(31.5)$ \\
S/A coronary artery bypass & $3(3.3)$ & chronic renal failure & $13(14.1)$ \\
systemic hypertension & $43(46.7)$ & CNS disorders & $8(8.7)$ \\
smoking & $14(15.2)$ & others & $7(7.6)$ \\
\hline
\end{tabular}

* COPD: Chronic obstructive pulmonary disease

$\dagger$ hyperlipidaemia, gout, hypothyroidism

$\$$ impaired level of consciousness, S/A stroke, myelodysplasia

$\S$ peptic ulcer disease, anaemia, asymptomatic carotid arterial narrowing, polyarthralgia

10-20 $\mu \mathrm{g}$ was used in 12 patients anaesthetized with bupivacaine. The observed sensory level was $\mathrm{T}_{4}-\mathrm{T}_{8}$, and all patients achieved satisfactory anaesthesia.

Intravenous sedatives and analgesics (i.e., $1-5 \mathrm{mg}$ midazolam, $1 \mathrm{mg}$ droperidol, 25-100 $\mu \mathrm{g}$ fentanyl and $300-600 \mu \mathrm{g}$ alfentanil), were used in 19, one, five, and three patients, respectively. Anaesthetic duration, fluid administration, the use of sympathomimetic drugs, the appearance of PDPH and the need for epidural blood patch are presented in Table II. Haemodynamic variables are presented in Table III.

Sympathomimetic drugs were needed for the treatment of hypotension in nine patients (11\%) in the preplanned group and in six patients (33\%) in the inadvertent group. Ephedrine was used in 12 parients (six in each group), at a dose of $5-25 \mathrm{mg}$ in $5 \mathrm{mg}$ increments. Five patients received $5 \mathrm{mg}$, one received $7.5 \mathrm{mg}$, three received $10 \mathrm{mg}$, and three received $15 \mathrm{mg}, 20 \mathrm{mg}$

TABLE II Clinical detail

\begin{tabular}{ll}
\hline Duration $(\min )^{\star}$ & $92.1 \pm 31.9$ \\
Fluids $(\mathrm{ml})^{\star}$ & $1330 \pm 578$ \\
Sympathomimetics $(\mathrm{n})$ & $15(15 \%)$ \\
PDPH $(\mathrm{n})^{\dagger}$ & $6(6 \%)$ \\
Epidural blood patch $(\mathrm{n})$ & $1(1 \%)$ \\
\hline
\end{tabular}

* Mean \pm SD

${ }^{\dagger} \mathrm{PDPH}=$ Post dural puncture headache

TABLE III Hacmodynamic variables

\begin{tabular}{ll}
\hline Baseline systolic BP (mmHg) & $147.8 \pm 22.9$ \\
Maximal systolic BP decreasc (\%) & $19.0 \pm 9.8$ \\
Baseline diastolic BP (mmHg) & $84.5 \pm 12.4$ \\
Maximal diastolic BP decrease (\%) & $13.4 \pm 13.3$ \\
Baseline HR (bcats per minute) & $80.3 \pm 13.7$ \\
Maximal HR decrease (\%) & $7.2 \pm 11.7$ \\
\hline
\end{tabular}

BP: blood pressure, mean \pm SD

HR: heart rate, mean $\pm S D$ and $25 \mathrm{mg}$ each. Phenylephrine was administered to two patients (CSA-P), at a dose of 100 and $150 \mu \mathrm{g}$, in $50 \mu \mathrm{g}$ increments. Both drugs $(5 \mathrm{mg}$ and $50 \mu \mathrm{g}$ ) were used in one patient (CSA-P). Post dural puncture headache appeared after six CSAs, but in only two (2.5\%) of the preplanned group. Four of these were male, and two female. The ages of these patients were $76,70,67,65$, 43 and 40 yr. One patient received an epidural "blood patch," while another was treated with an epidural injection of morphine. ${ }^{11}$ In both patients, treatment resulted in resolution of pain. In the other four patients, satisfactory pain relief was achieved by intravenous fluid loading and systemic analgesics. No postanaesthetic neurological deficit was detected in any of our patients.

\section{Discussion}

This study describes the use of continuous spinal anaesthesia with a standard $20 \mathrm{G}$ epidural catheter as an effective and safe anaesthetic approach for ESWL, and specifically in high risk patients.

Continuous spinal anaesthesia combines the advantages of both epidural and spinal anaesthesia: failure rate is very low as placement of the Tuohy needle in the subarachnoid space is easily ascertained by the escape of $\operatorname{CSF}^{1,2,6,12}$ Onset of anaesthesia is easy to control and can be either gradual, ${ }^{1,12}$ or rapid, ${ }^{1}$ depending on the sequence of injection of the LA. The administered dose of LA is small ( $9.7 \pm 7.5 \mathrm{mg}$ bupivacaine in our study), reducing the possibility of systemic toxicity if the catheter is accidentally inserted intravascularly. ${ }^{1,2}$ The sensory level of anaesthesia can be adjusted by careful titration, ${ }^{1,5,6}$ thus reducing the risk of haemodynamic instability. ${ }^{5,6}$ As the level of the block is established after patient positioning, haemodynamic $\mathrm{i}^{1,2,5,12}$ and respiratory ${ }^{5}$ stability may be better preserved. Duration of the block is unlimited due to the possibility of repeated injections via the spinal catheter. ${ }^{1,12}$ With the use of low 
doses of LA, the recovery time is usually short. ${ }^{1,5,12}$ The deep motor and sensory blockade achieved provides excellent analgesia and tends to eliminate movement which can disturb calculi fragmentation.

All patients achieved satisfactory anaesthesia. This may be related to the injection of the LA into the subarachnoid space. However, since the use of microcatheters may be associated with technical failure ${ }^{1-3}$ and with anaesthetic maldistribution ${ }^{3,7-9}$ our success may be related to the use of $20 \mathrm{G}$ catheters.

Hypotension is one of the disadvantages of "single shot" spinal anaesthesia ${ }^{13,14}$ which can cause considerable morbidity and mortality. ${ }^{13}$ It may be additive to the haemodynamic changes associated with ESWL, related to patients positioning and to the immersion in the water bath. The head-up positioning leads to peripheral pooling of blood and thereby to diminished venous return to the heart. This, however, may be offset by a possible increase in venous return due to immersion in water. ${ }^{10}$ In addition, the warm water in the bath may lead to vasodilatation, and therefore decreased blood pressure.

Prophylactic $i v$ infusion of crystalloids, or ephedrine, failed to prevent severe hypotension after "single shot" spinal anaesthesia in $\mathbf{5 5 \%}$ and $22 \%$ of patients, respectively. ${ }^{13}$ In contrast, although volume loading and sympathomimetics were not used prophylactically in our study, and despite the $T_{4}-T_{8}$ sensory level of anaesthesia, the average BP decrease was only 13.4-19.0\% (12.9-14.0\% in the CSA-P group). Moreover, administration of sympathomimetics for BP control was needed in only $15 \%$ of our anaesthetics, compared with $65 \%$ of the patients receiving "single shot" spinal anaesthesia for lower limb surgery in another study. ${ }^{2}$

We used 1-3 mg boluses of bupivacaine, comparable to the dosage range suggested by Sutter et al. ${ }^{2}$ Gradual titration of LA according to clinical response allows the circulation to accommodate to the vasodilatation induced by the CSA, thus minimizing the decrease in BP. As long as the block is kept below the $\mathrm{T}_{4}$ dermatome, cardioaccelerator sympathetic nerves can still react to hypotension. This enables the clinician to use CSA in patients that cannot tolerate wide fluctuations in BP, HR and/or rapid and massive volume loading. Several of the high risk patients in our study received $<500 \mathrm{ml}$ crystalloid during the procedure, while still maintaining haemodynamic stability. However, fluid administration was not restricted, since high urinary output was encouraged to flush calculi fragments from the urinary system. Despite the use of the wide-bore 18G Tuohy needle and standard epidural catheter, there was a low incidence PDPH, and no neurological sequelae were encountered.
The use of microcatheters (i.e., 28-32G) for CSA, was introduced in an attempt to reduce PDPH ${ }^{1,3,7}$ but it was found to be technically difficult to thread the microcatheter into the subarachnoid space despite good CSF flow through the needle., $1,3,7$ Using epidural sets, however, makes subarachnoid catheter insertion technically simple. The use of microcatheters was later abandoned following several reports of postanaesthetic cauda equina syndrome. ${ }^{3,6-9,15}$

The incidence of PDPH, which decreases with patient age, but increases with needle diameter, ${ }^{16}$ was low (2.5\%) in our CSA-P group despite the use of the $18 \mathrm{G}$ needle. This is in accordance with the $1 \%$ incidence found by others. ${ }^{4,17}$ The explanation for the reduced incidence of PDPH after CSA is not known. Perhaps an early inflammatory response develops in the dura surrounding the catheter at the puncture site, so that when the catheter is removed, fibrinous exudate and/or oedema seal the hole in the dura, thus preventing leakage of CSF. ${ }^{4,17}$ Adverse neurological sequelae after CSA may be related to the small diameter of microcatheters, ${ }^{3,8,9,15}$ or to a high LA dose ${ }^{8,18}$ or concentration. ${ }^{9,18}$ However, such a complication occurred even after CSA was performed with macrocatheters. ${ }^{19}$ Hence, it is possible that the lack of adverse neurological sequelae in our patients may be related to the relatively large diameter of the catheter, or to the low LA dose and concentration used. It is possible that such a complication could have been detected in a larger study population.

In summary, the results of this study suggest that CSA, utilizing standard $20 \mathrm{G}$ epidural catheters, can be performed effectively and safely in patients undergoing ESWL. Moreover, if the epidural needle is inadvertently introduced into the subarachnoid space during attempted epidural blockade, the catheter may then be intentionally inserted, and CSA carried out. In elderly patients for ESWL, however, and especially in high risk individuals, preplanned CSA is particularly desirable, since slow titration of LA to achieve the required sensory level seems to result in relative haemodynamic stability despite minimal use of pre-emptive volume-loading or cardiotonic agents. Despite the use of a relatively large diameter needle, the incidence of post dural puncture headache is low.

\section{References}

1 Hurley RJ. Continuous spinal anesthesia. Int Anesthesiol Clin 1989; 27: 46-50.

2 Sutter P-A, Gamulin Z, Forster A. Comparison of continuous spinal and continuous epidural anaesthesia for lower limb surgery in elderly patients. A retrospective study. Anaesthesia 1989; 44: 47-50. 
3 de Andrés J, Bellver J, Bolinches R. Comparison of continuous spinal anaesthesia using a 32-gauge catheter with anaesthesia using a single-dose 24-gauge atraumatic needle in young patients. $\mathrm{Br} J$ Anacsth 1994; 73 : 747-50.

4 Denny $N$, Masters $R$, Pearson D, Read J, Sibota $M$, Selander $D$. Postdural puncture headache after continuous spinal anesthesia. Anesth Analg 1987; 66: 791-4.

5 Underwood RJ. Experiences with continuous spinal anesthesia in physical status group IV patients. Anesth Analg 1968; 47: 18-26.

6 Shroff PK, Skerman JH, Blass NH. Continuous spinal blockade: an old technique revisited. South Med J 1988; 81: 178-80.

7 Turino M. Assessment of preformed, coiled-tipped, micro spinal catheter. Br J Anaesth 1994; 73: 655-7.

8 Schell RM, Brauer FS, Cole DJ, Applegate RL II. Persistent sacral nerve root deficits after continuous spinal anaesthesia. Can J Anaesth 1991; 38: 908-11.

9 Rigler ML, Drasner K, Krejcie TC, et al. Cauda equina syndrome after continuous spinal anesthesia. Anesth Analg 1991; 72: 275-81.

10 Eldor J, Guedj P, Cotev S. Epidural morphine injections for the treatment of postspinal headache (Letter). Can J Anaesth 1990; 37: 710-1.

11 Giuffrida JG, Bizzarri DV, Masi R, Bondoc $R$. Continuous procaine spinal anesthesia for cesarean section. Anesth Analg 1972; 51: 117-24.

12 Gajraj NM, Victory RA, Pace NA, Van Elstraete $A C$, Wallace $D H$. Comparison of an ephedrine infusion with crystalloid administration for prevention of hypotension during spinal anesthesia. Anesth Analg 1993; 76: 1023-6.

13 McCrae AF, Wildsmith JAW. Prevention and treatment of hypotension during central neural block. $\mathrm{Br} \mathrm{J}$ Anaesth 1993; 70: 672-80.

14 Behnia $R$, Shanks CA, Ovassapian A, Wilson LA. Hemodynamic responses associated with lithotripsy. Anesth Analg 1987; 66: 354-6.

15 Rigler $M L$, Drasner $K$. Distribution of catheter-injected local anesthetic in a model of the subarachnoid space. Anesthesiology 1991; 75: 684-92.

16 Vandam $L D$, Dripps $R D$. Long-term follow-up of patients who received 10,098 spinal anesthetics. JAMA 1956; 161: 586-91.

17 Peterson DO, Borup JL, Chestnut JS. Continuous spinal anesthesia. Case review and discussion. Reg Anesth 1983; 8: 109-13.

1.8 Rigler $M L$, Drasner $K$, Krejcie TC, et al. Cauda equina syndrome after continuous spinal anesthesia. Anesth Analg 1991; 72: 275-81.
19 Horlocker TT, McGregor DG, Matsushige DK, et al. Neurologic complications of 603 consecutive continuous spinal anesthetics using macrocatheter and microcatheter techniques. Anesth Analg 1997; 84: 1063-70. 